\title{
Preface
}

The Stanza dei Filosofi in the Capitoline Museum in Rome is a room filled with scores of busts of famous ancient poets, orators, and philosophers. The busts have been renumbered and rearranged several times in the past three centuries. ${ }^{1}$ Since its arrival in the museum in 1743 , the double herm of Epicurus and his placid follower Metrodorus has stood in the same place at the end of the main axis of the room (see the frontispiece and figure 12). That the piece has stayed put through the centuries is remarkable, for the position is special and hence vulnerable. It is a place of focus, orientation, and power. That Epicurus has occupied it against the competition of virtually the whole corpus of ancient Greek portraits speaks volumes about the magnetism of his image.

This book is a study of that magnetism. It is a test of the validity of my suspicion that my own experience of overwhelming power in Epicurus' portrait when I first saw it in the Capitoline Museum seven years ago was not merely a personal reaction but the response intended by the thirdcentury B.C. artist who sculpted it and by the Epicureans who commissioned it. Ancients like Cicero's friend Titus Pomponius Atticus and moderns like the distinguished art-historian Frederik Poulsen have described how unforgettable the portrait of Epicurus is and how strong a hold it takes upon the

I. See H. S. Jones, A Catalogue of the Ancient Sculptures Preserved in the Municipal Collections of Rome. The Sculptures of the Museo Capitolino, vol. I (Oxford 19I2) 8-9, where one such rearrangement is discussed. 
xiv Preface

minds of those who view it. ${ }^{2}$ My purpose in writing this book is to give a philosophical, art-historical, and sociopsychological explanation of that fascination.

Of course, the fascination of a statue is not a topic about which one can sensibly write at great length, since it involves intuitive and emotional faculties that do not lend themselves to extended analysis. Most of this book is taken up with matters a good deal more mundane, which serve to prepare a secure route for approaching this elusive goal. Because the itinerary involves taking several vie tortuose, it will be well to begin by giving an overview.

In the first chapter ("Philosophy and Society in Greece"), I discuss the Epicurean school's manner of interacting with Greek society compared to that of the other philosophical schools. Whereas the other schools form a subculture whose members' status in the dominant culture ranges from high integration to complete alienation, the Garden of Epicurus is an alternative community under the charismatic leadership of a godlike master. In alternative communities, like the Garden, that do not recruit from within by training members' children to perpetuate the organization, new converts must be sought from the dominant culture. Since the Epicureans imposed on themselves rules limiting contact and even communication with the world outside their school, the manner in which they could recruit members from the dominant culture is problematic.

In the second chapter ("A Reconstruction of the Epi-

2. See Cicero, De finibus 5. I.3; F. Poulsen, "Au jardin d'Epicure," Gazette des Beaux-Arts (I937.I) 8-9. Poulsen's statement, while a valuable subjective report of the experience of seeing Epicurus' portrait, is very bad scholarship. He writes: "Selon Cicéron, son ami Atticus, qui lui-même était epicurien, écrivait: 'nec tamen Epicuri licet oblivisci, si cupiam.' Ces mots peuvent aussi être employés au sujet de la tête d'Epicure, car c'est un des portraits antiques qu'on oublie le moins et qui se confond le plus difficilement avec d'autres." Note, first of all, that according to Cicero ( $D e$ fin. 5.I.3), Atticus spoke these words, he did not "write" them. Furthermore, he was already applying them to the subject of Epicurus' bust, despite what Poulsen might lead one to believe. Finally, for interesting reasons that will be discussed at the end of Chapter III, Epicurus' head is easily confused with other ancient heads, namely, those of his followers Metrodorus and Hermarchus. 
curean Policy on Recruitment and Conversion"), I reconstruct the Epicurean policy on recruitment as a hypothetical Epicurean theorist might have done. The Epicureans faced the dilemma of how to retreat from the dominant culture while still bringing a message of salvation to mankind. I suggest that they solved this dilemma in accordance with their own theory of motivation. According to this theory, in a healthy individual perception, cognition, feeling, and motivation occur simultaneously. What we perceive, we understand and experience as pleasure or pain. If a percept is painful, we naturally try to suppress it as soon as possible. If it is pleasant, we are motivated to preserve it and to imitate it so that we become a source of pleasure to ourselves. The problem of recruitment can be viewed as the problem of motivating people to become Epicureans. Applying their own general theory to this special case should have made the Epicureans recruit by disseminating pleasing images of wisdom-that is, of the blessed and happy wise man-among as great a number of people as possible. In this way, the dilemma of recruitment could be solved by permitting the sage to perfect himself - and his image-in retreat from the world, while sending his image out into the world to do the work of recruitment for him.

The solution to this dilemma creates another problem. There are obvious practical limitations on the sage's ability to transmit his image. It cannot penetrate the physical barriers separating the Garden from the rest of the city. It cannot outlive the sage. It cannot always show the sage at his best. An artistic (or, "secondary") image of the sage's actual (or, "primary") image can make up for these shortcomings by being erected in public places in the city, by surviving long after the sage's death, and by presenting the sage to his best advantage. In the third chapter ("From Theory to Practice"), I survey the archaeological remains of Epicurean artistic images to show that the statistics concerning preserved portraits of ancient philosophers confirm the guess that, because of their approach to recruitment, the Epicureans commissioned far more portraits of their masters than did their competitors, whose philosophies made interaction with the dominant culture far more direct and easy. After a digression justifying use 


\section{xvi Preface}

of the tabu term fetishism in analyzing Greek religion, I link the Epicureans' use of portraits as effective means of communication and motivation to this fundamental feature of Greek popular religion. That Epicurean theology is today recognized to be a theoretical version of Greek popular religion I take as important evidence in favor of this claim. If many Greeks attributed powers of communication and motivation to statues, then the Epicureans were likely to have agreed, although they would have linked these powers to materialistic, not magical, processes.

While the policy reconstructed in Chapter II gains statistical and cultural support in Chapter III, that support cannot weigh as heavily as a study of the iconology of Epicurus' portrait. In lieu of explicit written documentation of the policywhich we are, alas, unlikely ever to recover-the best possible available evidence in favor of the reconstruction is proof that the portrait is a "sculpted word" conveying crucial messages about Epicurus' character and mission to mankind. Before the iconology can be studied, the fragmentarily preserved ancient statue of Epicurus must be put back together and dated and its original location determined, in order to provide the hermeneutical framework for interpretation. This is the purpose of Chapter IV ("Iconographical Problems"), ${ }^{3}$ in which I show that the statue was probably commissioned by the Epicurean school for public erection in

3. My titles in Chapters IV and V are inspired by Erwin Panofsky's distinction between iconography and iconology, on which see C. Hasenmueller, "Panofsky, Iconography, and Semiotics," Journal of Aesthetics and Ant Criticism 36 (1978) 289-302. Note that Panofsky's terms are specifically designed for application to Renaissance art (see his essay, "An Introduction to the Study of Renaissance Art," in Meaning In the Visual Arts [Garden City, New York 1955] 26-54). As applied to Hellenistic art, they must, I think, be somewhat modified in substance, if not in method. For Panofsky, iconography deals with "images, stories, and allegories" (p. 35); iconology concerns "the intrinsic meaning of the work . . . [in comparison with] the intrinsic meaning of . . . other documents of civilization historically related to that work" (p. 39). As I use the terms here, iconography deals with what might be called the "philological" discipline of reconstructing, identifying, dating, and attributing the work of art (cf. pp. 3I-32, where Panofsky speaks of iconography as a descriptive discipline), whereas iconology deals with the interpretation of the work of art in both werkimmanent and -transcendent terms. 
Preface xvii

Athens (near the Pompeion?) during the period 280-250 B.c. Reconstructing the lost original version of the statue takes up most of this chapter, primarily because a good deal of space must be spent on a digression in which I explain why a recent reconstruction based on an eighteenth-century engraving is wrong. My own reconstruction is based upon ancient copies of the statue that show Epicurus deep in thought and about to speak, dressed in a himation and seated on a solid-sided throne. In his left hand he holds a book-roll. The left arm rests across Epicurus' waist, and he stretches his right hand forward toward an imaginary observer, in a gesture of teaching or greeting.

In the last chapter ("Iconological Problems"), the iconology of the statue is examined, with the result that Epicurus is seen to be portrayed according to the conventions of contemporary Greek art as a philosopher, father-figure, Asklepian healer, Herculean culture-bringer, megalopsychos ("greatsouled" man), and god. Such a complex message could be designed into Epicurus' portrait because its sculptor was ingeniously able to fill in details left undetermined by the requirements of one type with the details dictated by the other types. Thus, the philosopher-type dictated the clothing, coiffure, and book-roll. The father-figure determined the pose and gesture of the body. The Asklepian type inspired the expression on the face. The Herculean type governed the proportions of the head. The megalopsychic type was responsible for many, seemingly trivial, physiognomical traits. The god-type influenced the shape of the throne on which Epicurus is seated.

In order to add a final degree of plausibility to my interpretation of the iconology and propagandistic function of Epicurus' portrait, I conclude the book with discussions of late fourth-century B.C. theories of the typological presentation of character in the arts and of twentieth-century theories of conscious and unconscious motivation for renewal of the self. Both discussions are intended to show the historical and universal reasons why the Epicurean approach to recruitment is likely to have been effective in drawing to the school precisely those strangers who, upon immersion into Epicurean doctrine, were dispositionally best suited to accepting the be- 
xviii Preface

liefs of the school, viz., the personality-type that Jung characterized as extraverted thinking-sensation.

II

The manuscript of this book was essentially completed in January 1979 , so literature appearing in or after 1978 could only rarely be taken into account. A. F. Stewart's important monograph, Attika: Athenian Sculpture from c. 320 B.C. to 14 A.D., JHS Supp. Paper I4 (I979), did not reach Los Angeles in time to be consulted, nor did H. Protzmann's equally valuable essay, "Realismus und Idealität in Spätklassik und Frühhellenismus," JDAI 92 (1977) I69-203 (it did not arrive here until 3I May I978). I am pleased to note that on page I77 Protzmann has independently observed the similarity of the expressions of Epicurus and the Asklepios of Melos (a similarity I first pointed out in public lectures during JanuaryMarch 1976 at the University of North Carolina [Chapel Hill], Wesleyan University, and the American Academy in Rome).

For an excellent new study of what in Chapter IV I call the "civic pride movement" of the first and second centuries A.D., see now C. P. Jones, The Roman World of Dio Chrysostom (Cambridge, Mass. and London 1978). The Hellenistic sources of Diogenes Laertius-on which I rely in my wissenssoziologische analysis of Greek philosophy in Chapter I- have been studied anew by J. Mejer, Diogenes Laertius and His Hellenistic Background, Hermes Einzelschrift 40 (1978). The appearance of $\mathrm{H}$. Funke's article on Götterbild in RAC 85/86 (Stuttgart I98I), with its full discussion of fetishistic aspects of Greek beliefs about divine statues (in cols. 7I3-I4), makes me feel much less lonely than I did when I originally wrote my digression on fetishism in Greek religion in Chapter III. My discussion of the presentation of character in Hellenistic art may now be supplemented by the brief, but stimulating, remarks in J. Onians, Art and Thought in the Hellenistic Age (London 1979). Finally, I am pleased to be able to report that my Kopienkritik and reconstruction of Epicurus' statue in Chapter IV are in substantial agreement with the results re- 
Preface xix

cently published by V. Kruse-Berdolt in her Göttingen dissertation on the Epicurean portraits. ${ }^{4}$

In this book, I discuss again two topics on which I have previously published. In Chapter II, the discussion of the Epicurean policy on recruitment supersedes that to be found on pp. 199-222 of my At Tu Aureus Esto: Eine Interpretation von Vergils 7. Ekloge (Bonn 1975). My analysis in Chapter IV of the background of the Bouchardon-Preisler engraving of Epicurus' portrait replaces that in my article in California Studies in Classical Antiquity for 1979. Besides being justified by the demands of my present argument, the inclusion of this material here is, I think, warranted by the incorporation of insights and evidence that have come to my attention since I wrote the passages in question.

4. V. Kruse-Berdolt, Kopienkritische Untersuchungen zu den Porträts des Epikur, Metrodor, und Hermarch (Diss. Göttingen 1975) (despite the publication date of 1975 , the work was not available-at least at the DAI Rome-until late I980).

Kruse-Berdolt and I are in agreement that BI Richter (=E $32 \mathrm{~K}-\mathrm{B}$ ) belongs to the small group of excellent copies (my Group I, in Chapter IV, section xiii below) on the basis of which a reconstruction of the lost Hellenistic original may be attempted. Thus, it is not surprising that our reconstructions of Epicurus' face are quite similar (cf. Kruse-Berdolt, pp. I28-29 with Chapter IV, section xiv below). Kruse-Berdolt may, however, be criticized for including in this group a very damaged head in Copenhagen (her E I3 $=\mathrm{B}_{21}$ Richter) and a head in the Louvre (her $\mathrm{E}$ $27=\mathrm{B}_{\mathrm{I}} 8$ [not B I7, as Kruse-Berdolt erroneously states] Richter) that does not quite reach the highest degree of fidelity and state of preservation required for inclusion in this group. She may also be criticized for omitting from this group the excellent bronze bust B 8 Richter (=E 2I K-B) as well as the marble bust inv. nr. 197306 in the Museo Nazionale delle Terme in Rome (=E $34 \mathrm{~K}-\mathrm{B}$ ). (I do not mention her omission of the small marble bust $\mathrm{G} 23$ in the J. Paul Getty Museum, because I am publishing it here for the first time.)

Kruse-Berdolt has admirably increased the list of known copies of both the torso and the bust of Epicurus. First listed by her in a comprehensive catalogue of Epicurus copies are: $\mathrm{E}_{4}$ (a marble torso in the Bursa Archaeological Museum); E I I (a small basalt head, inv. nr. Sk I8I I in the Berlin Staatliche Museen); E I6 (a small bronze bust in the Archäologisches Institut der Universität Leipzig); E I9 (a marble head, inv. nr. 540 in the Museo Arqueológico in Málaga); and E 34 (a marble head in the magazines of the Museo Nazionale delle Terme in Rome; the head apparently lacks an inventory number). Except for $\mathrm{E}_{34}$, all the other newly reported copies 
belong to my Group IV (heavily restored, unfinished, worn, and/or fragmentary copies) - at least to judge from Kruse-Berdolt's verbal descriptions of them (unfortunately, she publishes no photographs of the pieces)so that their absence from Chapter IV, sections xiii and xiv, will not affect the validity of my results. Kruse-Berdolt has a high regard for E 34, and so it is a pity that she was not able to publish the piece or take it into account for her own work. I regret that I have also not been able to do so.

One point of significant disagreement between me and Kruse-Berdolt concerns the reconstruction of Epicurus' right arm. Since this is the only major element of the statue not attested by ancient evidence, disagreement is understandable and, perhaps, inevitable. Nevertheless, since the reconstruction of the right arm is rather important for interpretation of the portrait, I take this opportunity to bolster my hypothesis that the right arm was extended forward in a gesture of teaching or greeting by arguing against Kruse-Berdolt's speculation that the arm was turned back toward the upper chest as if stroking-or about to stroke-the beard.

Kruse-Berdolt makes the following four arguments in favor of her reconstruction of the right forearm and hand: ( $\mathrm{I}$ ) two copies preserve supports for the elbow on the inner side of the wrist. If the right forearm jutted forward, we would have expected the elbow to rest "directly on the wrist" (p. I 49). (2) The "speaking" or "disputing" gesture of the hand is "practically not attested" in the surviving corpus of Greek portraits (p. I49); the possible parallel of Poseidippos (Vat. inv. nr. 735=Richter, Portraits of the Greeks, vol. 2, pp. 238-39, figs. I647-50) is not applicable "on account of the different positioning of the arms" (p. 149). More frequent is the forearm angled back toward the beard (p. I 50). (3) A "disputing" gesture would contradict the "stern and self-contained structure" of the portrait (p. I 5o). (4) The gesture of beard-stroking accords well with the position of the head, which, according to Kruse-Berdolt, was "not only turned toward his left side, but was also inclined a bit toward the right" (p. I 50). Thus, the attitude of the head suggests a pose of inward meditation, not teaching.

None of these arguments withstands scrutiny. The second argument is based on the statistics of the surviving corpus of Greek portraits. It is invalid not only because too few torsos survive to permit such statistical arguments, but also because forearms raised up and back toward the upper chest (to which they were sometimes braced) were much more likely to survive intact than were vulnerably forward-thrusting forearms. The point about Poseidippos is merely special pleading, and no cognizance is taken of ancient literary sources (like Sidonius, epist. 9.9.14) which attest portraits with oratorical gestures. The first argument purports to present a technical reason against a forward-thrusting right forearm, but why the elbow of such an arm could not rest on the inner side of the wrist escapes me. Equally mistaken is the third argument. Here we may readily accept the principle that the body language of the statue ought to reflect the expression of the face. However, Kruse-Berdolt misreads the face by failing to 
It is a pleasure to put on record my gratitude to two groups of readers who were kind enough to give me their reactions to various drafts of sections of this book. Margarete Bieber, Frank Brown, Stanley Burstein, David Furley, David Konstan, Knut Kleve, Ingrid Rowland Lacy, Steven Lattimore, Wolfgang Lotz, Charles Mitchell, Martin Robertson, and Bruce Rosenstock all expressed their support of my project-which at times seemed interminable-and, despite disagreements over details, encouraged me to persevere with it when I was beset with self-doubt. Malcolm Bell, Peter Carl, Helga von Heintze, Eva Keuls, Rebecca Miller, Thomas Schweitzer, Andrew Stewart, and an anonymous reader for

consider the meaning of the slightly parted lips that she herself notes on p. 128 of her study. Are we to imagine that Epicurus is muttering to himself as he is lost in meditation? Parted lips imply an expression of speaking-as does an outstretched right forearm. The fourth argument gets to the heart of the matter. Kruse-Berdolt is motivated to restore the right forearm as she does and to ignore the open mouth because of her dubious reconstruction of the inclination of the head. According to her, bust $\mathrm{E} 33$ (=Mus. Cap. inv. nr. 577, Stanza dei Filosofi nr. 53; Richter, Portraits of the Greeks, vol. 2, p. I95, nr. 2, figs. I I I $-\$ 2$ ) is our best copy for the "hair system"; her detailed study of this system has persuaded her that Epicurus' hair is falling in such a way that the head of the original (if not of bust $E_{33}$ ) must have been directed slightly downward and to the left. There are two decisive objections that must be raised against this argument. First, KruseBerdolt nowhere establishes the reasons for giving bust $\mathrm{E} 33$ pride of place when the problem of analyzing Epicurus' coiffure is confronted. Second, bust $\mathrm{E} 33$ is a particularly unreliable witness of the major physiognomical details of the face, as Kruse-Berdolt herself openly admits (p. I28). Thus, far from establishing the priority of bust E 33, Kruse-Berdolt succeeds only in disqualifying it from consideration as a useful witness of any of the characteristics of the Hellenistic original of Epicurus' portrait. Once E 33 is eliminated, no evidence remains in favor of Kruse-Berdolt's restoration of the inclination of Epicurus' head. Once we have no reason to imagine Epicurus' head turned downward to the left, we also have no reason to imagine Epicurus lost in thought and completely oblivious of the world around him. The way is thus reopened to restoring the right forearm in a way that accords with the sympathetic furrow across Epicurus' forehead, his forward-gazing, sharply focused eyes, and with his slightly parted lips-viz., as thrusting forward in a gesture as communicative as is the expression on his face. 
xxii Preface

the University of California Press played in their various ways the role of Horace's Quintilius by insisting that I put aright even the smallest flaws they could discover.

Deborah Nourse Lattimore put her talented services at my disposal in preparing drawings of my reconstruction of the statue of Epicurus and a map of the Villa Ludovisi. Brunilde Ridgway and Helga von Heintze sent me useful comments about an earlier drawing reconstructing the statue of Epicurus. Madame Peppas Delmousou kindly sent me photographs of Greek inscriptions in the Epigraphical Museum in Athens, and she also went far beyond the call of duty in measuring all the herms in her charge. I must also thank George Dontas, Karin Einaudi, and Jiř́ Frel for sending me the photographs I requested. Crucial clerical help in preparing a complicated manuscript was provided by Tracy Caulfield, Elizabeth Farny, Monica Rothschild, and Charitini Velissariou. My copy editor, Jane-Ellen Long, deserves my gratitude for her work in correcting my manuscript, as do my editors Doris Kretschmer and Mary Lamprech for their help in seeing this book through to publication. Various acts of Epicurean amicitia were performed during the writing of this book by my friends Princess Minnie de Beauvau-Crâon, Karin and Roberto Einaudi, Maria Julia de Ruschi Crespo, Gesche and Volkart Olbrich, Ann and Russell T. Scott, and Antonio and Annabelle von Marx. My wife's devotion to me during the period when this book was being written surpassed, if it is possible, even the infinite limits of the marriage vow.

I am extremely grateful to the following museums, libraries, and archives for allowing me to use, and in some cases to publish, material in their collections: Algemeen Rijksarchief (Den Haag); Archivio Segreto Vaticano; Biblioteca Hertziana; Biblioteca Nazionale (Rome); Biblioteca Vallicelliana; Biblioteca Vaticana; Bibliothèque Nationale (Paris); British Museum; Cabinet des Dessins du Musée du Louvre; Epigraphical Museum (Athens); J. Paul Getty Museum; the Library of the American Academy in Rome; the Library of the C. G. Jung Institute (Los Angeles); the Library of the German Archaeological Institute (Rome); Musée du 
Louvre; Musei Capitolini; Musei Vaticani; Museo Nazionale di Napoli.

I could never have visited all of these research institutes or have had the time necessary to write this book were it not for the generous financial support given me by the American Academy in Rome and the Academic Senate of the University of California at Los Angeles. For their help in supporting my applications for research grants and in providing a stimulating environment in which research could be undertaken, I wish to thank my colleagues in the UCLA Department of Classics. The dedication of this book is my small way of thanking the American Academy in Rome for giving me: a research fellowship in the years 1974-1976; an appreciation for how interdisciplinary work in classics and archaeology can still be pursued in this age of specialization; and a model for what life must have been like in the Garden of Epicurus.

Los Angeles

31 March 1981 
